\title{
Outcomes following arthroplasty for proximal humeral fractures
}

\author{
Tony Antonios ${ }^{a,}{ }^{*}$, Nik Bakti $^{\mathrm{b}}$, Akshay Phadkhe $^{\mathrm{b}}$, Abhinav Gulihar ${ }^{\mathrm{c}}$, Bijayendra Singh ${ }^{\mathrm{b}}$ \\ ${ }^{a}$ Department of Trauma \& Orthopaedics, King's College Hospital NHS Foundation Trust, Denmark Hill, London, SE5 9RS, UK \\ ${ }^{\mathrm{b}}$ Department of Trauma \& Orthopaedics, Medway NHS Foundation Trust, Windmill Road, Gillingham, Kent, ME7 5NY, UK \\ ${ }^{\mathrm{c}}$ Department of Trauma \& Orthopaedics, Princess Royal University Hospital, Farnborough Common, Orpington, BR6 8ND, UK
}

\section{A R T I C L E I N F O}

\section{Article history:}

Received 23 March 2019

Received in revised form 15 July 2019

Accepted 16 July 2019

Available online 24 July 2019

\section{Keywords:}

Proximal humerus

Fracture

Arthroplasty

\begin{abstract}
A B S T R A C T
Fractures of the proximal humerus are very common and increasing in incidence within an ageing population. The majority of undisplaced fractures can be treated conservatively. Displaced fractures in good quality bone or in the young are considered for surgical fixation. However, displaced and comminuted fractures with or without dislocation, especially in the elderly, cannot be reliably treated with fixation. These patients are generally considered for joint arthroplasty. This review article focuses on the outcome following arthroplasty for proximal humeral fractures.
\end{abstract}

(c) 2019 Delhi Orthopedic Association. All rights reserved.

\section{Introduction}

Proximal humeral fractures account for almost $10 \%$ of all fractures. ${ }^{1}$ Their incidence is rising with an aging population, accounting for a third of all fractures in the over 65 years of age with an expected further increase in the next 20 years. ${ }^{2}$ It is three times more common in women, with trauma secondary to low energy falls accounting for $90 \%$ of cases. ${ }^{2}$

The estimated cost to the health service and rehabilitation in a country with a similar population to the United Kingdom, is over $£ 80$ million. $^{3}$ In those over 65 years old, the burden of loss of independence and reliance on others for support has a profound effect on their mental and socioeconomic state. It also has a significant impact on the work life of individuals caring for these patients(3).

Treatment of proximal humeral fractures depends on fracture morphology, patient co-morbidities and expected outcome. The aim is to achieve a healed stable fracture in a pain free functional shoulder. This can be achieved conservatively or surgically. The literature supports conservative management for non-displaced or minimally displaced fractures. ${ }^{4}$ However, surgical management remains controversial when it comes to comminuted fractures. This is more so in the over 65 s due to poor quality bone in this patient group. ${ }^{5}$

\footnotetext{
* Corresponding author.

E-mail address: tantonios@doctors.org.uk (T. Antonios).
}

Currently there is no real consensus to establish superiority of open reduction and internal fixation (ORIF) to prosthetic replacement. ${ }^{1}$ The fixed-angle devices implanted in ORIF have substantially evolved over the past two decades to withstand the rotator cuff's biomechanics and resist fracture varus collapse. ${ }^{6}$ However, the literature shows a suboptimal clinical result in the over 65 years age group with a complication rate of $48.8 \%$ and revision rate of $13.8 \%$ according to two recent systematic reviews.

Consequently, proximal humeral prosthetic replacement in the form of hemiarthroplasty (HA) was implanted for complex or comminuted proximal humeral fractures. ${ }^{6,7}$ It was first designed and used by Neer in the 1950s due to the poor results achieved by other means of management. ${ }^{8,9}$ Neer classified proximal humeral fractures into different parts: greater tuberosity, lesser tuberosity, articular portion of the head and the humeral shaft. To be considered as parts, these structures must be angulated more than $45^{\circ}$ or displaced by more than $1 \mathrm{~cm}$. Initial evidence of an intact medial hinge results in a preserved blood supply and fixation should be considered. ${ }^{10}$ If lost, the avascular necrosis is reported to be up to $75 \%$. However, this has been refuted by more recent publication. This paper suggests that there is no increase in complication rate in particular avascular necrosis when the medial hinge is involved.

The most complex fractures are the ones likely to need a prosthetic replacement. This includes Neer's 3-4 part fractures, fracture dislocations, head splitting fractures, displaced anatomical neck fractures, or if more than $40 \%$ of the joint surface head is involved. ${ }^{11,12}$

Prosthetic replacement is a technically demanding procedure 
with complex mechanical considerations. Good functional outcome requires restoration of humeral height, implant retroversion, reasonable availability of bone stock, functioning musculature, and in the case of HA, anatomical reconstruction and healing of the tuberosities to restore cuff function. ${ }^{12,13}$ Cuff dysfunction occurs due to displacement of the tuberosities. In the case of an insufficient or non-functioning rotator cuff, shoulder replacement in the form of reverse polarity arthroplasty (hemisphere on the glenoid and socket on the proximal humerus) has gained popularity as an alternative to HA. ${ }^{14-16}$ This form of shoulder arthroplasty does not rely on the tuberosity healing and cuff integrity by recruiting the deltoid to restore functional mobility of the shoulder. ${ }^{14-16}$ The decision however to perform a reverse polarity shoulder replacement rests mainly on fracture configuration, patient age and occasionally on the premise of pre-existing cuff disease. Finally, surgical training, preference and experience have shown to play a major part in achieving satisfactory results in either techniques. ${ }^{11,17}$

This article review will focus on the outcomes of proximal humeral fracture management with prosthetic replacement.

\section{Evolving design}

The first shoulder arthroplasty was implanted in 1893 by a French surgeon named Pean. ${ }^{18}$ Neer in 1955 implanted the first modern HA prosthesis and used it primarily for proximal humeral fractures that could not be treated by other traditional methods. ${ }^{9}$ However, it was not until the early 1970s that his work was noted by the shoulder orthopaedic community, when he published the results of his case series showing $90 \%$ satisfactory outcome. ${ }^{9} \mathrm{He}$ later modified his implant to treat osteoarthritis and designed a polyethylene glenoid component. ${ }^{9,19}$

In the late 1970s and early 1980s, other designs came into the market which were predominantly modified successful hip arthroplasty systems. Despite different biomechanics to the hip joint, these systems employed similar concepts to the hip arthroplasty leading to early implant loosening, poor clinical outcomes and high complication rates. ${ }^{7,18}$ Later in the 1980 s, Neer modified his unconstrained design in the form of HA monoblock prosthesis, which showed excellent results in patients with no cuff abnormalities. ${ }^{19}$ Subsequently, modular implants appeared giving more options and sizes to match patient fracture configuration and bone stock. $^{18}$

In the 1990s, computerised measurements of fracture configuration allowing more accurate anatomic reconstruction revolutionised the prosthetic development and implantation which were more specific to patient anatomy. These were referred to as the third generation implants. ${ }^{20}$ The ability to dial in implant inclination, offset and head size allowed more accurate centre of rotation which results in better shoulder function. ${ }^{18,20}$

Total anatomical shoulder replacement, where the proximal humerus as well as the glenoid are replaced, is not a viable option in 3-4 part proximal humeral fractures. ${ }^{7,12}$ This is due to the high risk of rapid glenoid component loosening, polyethelene wear as well as the glenoid cartilage being generally healthy. ${ }^{12}$ However, the decision-making process is significantly different if the rotator cuff is injured or severely deficient. Unconstrained designs such as HA or anatomical shoulder replacement produced poor shoulder functional outcomes as their biomechanics rely on sound rotator cuff function. $^{12,18}$ Hence, constrained designs were preferred in these patients.

Initial constrained designs in the 1970-80s were discarded due to high failure rate secondary to loosening. ${ }^{18}$ In the late 1980 s, a French group developed an implant that reversed the polarity of the joint with the hemisphere in place of a glenoid and the socket in the proximal humerus. ${ }^{18,21}$ This modified joint geometry allows recruitment of the deltoid muscle for elevation of the arm to reestablish shoulder function. It is therefore a semi-constrained system as it relies on deltoid tension..$^{5}$ The system moves the centre of rotation medially and inferiorly toward the scapula. The medial shift reduces the forces applied to the glenoid and therefore, the risk of glenoid loosening. ${ }^{5}$ The inferior shift increases the lever arm of the deltoid and reduces reliance on a deficient or injured rotator cuff. ${ }^{22} \mathrm{~A}$ second design is now used - it positions the centre of rotation more laterally in the glenoid component. ${ }^{5}$ This reduces the work of the deltoid and increases stability, and may reduce wear.

With this increased popularity, the RSA indications further expanded to include other complex conditions such as glenoid or proximal humeral lesions needing graft reconstruction and proximal humeral fractures. $^{16}$

\section{Literature review}

\subsection{Hemiarthroplasty}

Previously, when ORIF is contraindicated or not possible, HA is considered the gold standard. ${ }^{19,23}$ This procedure has now been superseded as it is technically demanding and requires adequate restoration of normal anatomy. ${ }^{5,18,23}$ Besides trauma, HA is used in the treatment of degenerative and inflammatory glenohumeral conditions with intact rotator cuffs. ${ }^{11,18,23}$ Figs. $1 \mathrm{a}$ and $1 \mathrm{~b}$ are examples of pre and post operative radiographs of HA in proximal humeral fracture.

The first HA series in the literature reported $90 \%$ success rate in 43 patients with a mean age of 55.3 years and follow up between 1 and 16 years. ${ }^{9}$

The greatest influence on the success of HA is repair and healing
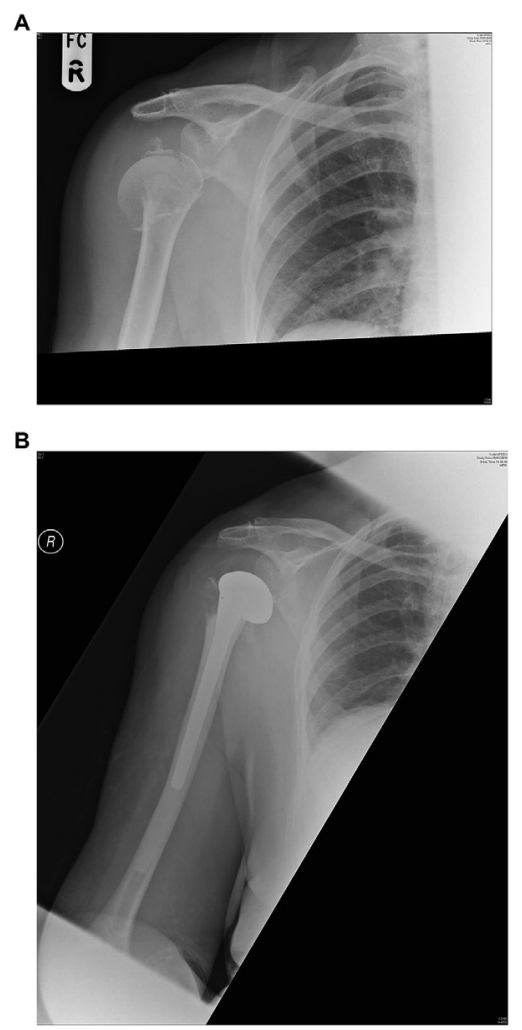

Fig. 1. a and b: Pre and post-operative radiographs of implantation of HA for a proximal humeral fracture. 
of the lesser and greater tuberosities. ${ }^{11,13}$ This can be optimised by restoration of humeral stem height and retroversion. ${ }^{11,13}$ Humeral lengthening of more than $1 \mathrm{~cm}$ or shortening of more than $1.5 \mathrm{~cm}$ or $40^{\circ}$ or more retroversion is likely to produce low Constant scores, i.e., poor functional outcomes. ${ }^{13}$

In 2003, an observational cohort study of 163 consecutive patients treated with primary HA showed good Constant scores with overall good functional outcomes in terms of pain, range of movement and survival of the implant; especially in young patients. $^{12}$ Furthermore, a multicentre retrospective study of 167 patients with 3-4 part fractures in 12 Austrian hospitals published in 2004, with follow up of more than a year, showed good Constant scores and excellent pain relief. ${ }^{11}$ This study also showed greater tuberosity healing significantly influences the outcome of surgery.

However, a systematic review published in 2008 combining 810 patients from 16 studies with a mean age of 67.7 years and mean follow up of 3.7 years, showed a combined Constant score function of only 57 out of $100 .^{24}$ This was derived from pain relief, range of movement, and strength.

Few published studies are available on the literature to compare the outcomes following HA to non-operative management or ORIF. In 1984, a prospective study comparing Neer HA monoblock to nonoperative management reported a better outcome in the HA group with respect to function, pain and muscle strength. ${ }^{25}$ Another study comparing HA with ORIF in 32 participants following 4-part fractures reported marginally better Disability of the Arm Shoulder and Hand (DASH) and Constant scores in the HA group following 24 months follow-up. ${ }^{26}$

In 2011, a randomised-controlled trial (RCT) of HA versus nonoperative management in 4-part comminuted fractures in 55 patients, with a mean age of 77 years, reported a significant advantage of quality of life and pain control in favour of HA but no difference in range of movement at 24 months follow up. ${ }^{27}$ However, a year later, another similar RCT of 50 patients showed no clear benefits in treating patients over the age of 65 years with either HA or nonoperative management in 4-part proximal humeral fractures. ${ }^{28}$ Furthermore, more recent studies showed average functional outcomes following HA especially in those over 65 years. The increased level of dissatisfaction led the authors to question its efficacy. ${ }^{13,24}$

There are also several complications associated with HA reported in the literature. ${ }^{24}$ Intraoperative complications include malpositioning, axillary nerve injury and iatrogenic fractures. ${ }^{12,24}$ Early postoperative complications include tuberosity repair pulloff (23\%), instability (15\%), joint stiffness (5\%) and infection (5\%). Late complications include glenoid erosion (35\%), heterotophic ossification (30\%), rotator cuff dysfunction (23\%), implant loosening (3\%) and periprosthetic fractures (2\%). ${ }^{11,12,27,28}$

Despite advances in the HA procedure, tuberosity non-union remains the main complication reported in the literature, with a rate of at least $20 \%{ }^{13}$ Moreover, the questionable quality of the rotator cuff, especially in the over 65 year olds, and motivation to strict rehabilitation protocol to allow healing of the tuberosities, showed worse outcomes in this patient group. ${ }^{18,23}$ This led to the increased popularity of implants which do not rely on the healing of the greater tuberosity or integrity of the rotator cuff tendons.

\subsection{Reverse shoulder arthroplasty}

RSA use has dramatically increased in the last two decades. $^{14,16,23}$ Initially, the semi-constrained design sought to address the shortfall in other replacement types to treat osteoarthritis in patients with pre-existing rotator cuff deficiency or injury. ${ }^{18,23}$ The RSA does not rely on tuberosity healing, an essential component of HA success. ${ }^{14,15}$ It was initially considered as salvage operation for failed HAs or the last resort when other approaches failed. ${ }^{21,29}$

In the United States, a cohort study looking at the surgical management of proximal humeral fractures of 38729 over 65 yearold patients between 2011 and 2013 found the rate of RSA increased by 1.8 fold from $14 \%$ to $24 \%$ from all operated cases $(p<0.001) .{ }^{30}$ In fracture management, RSA accounted for $53.3 \%$ of all arthroplasties in 2013 as opposed to $32.2 \%$ in 2011 . The same findings were echoed by a similar cohort study published in $2015 .{ }^{31}$ Furthermore, a retrospective case-control study from the New Zealand Joint Registry identified 313 HAs and 57 RSA for proximal humeral fractures. $^{32}$ The RSA group showed a significantly better Oxford Shoulder Score over a 5-year follow up $(\mathrm{p}<0.022)$ but no difference in revision rates. Figs. $2 \mathrm{a}$ and $2 \mathrm{~b}$ are examples of pre and post operative radiographs in RSA in proximal humeral fracture.

With higher efficacy and success rates, their popularity has increased dramatically and their use as primary implant for 3-4 part comminuted proximal humeral fractures has increased. ${ }^{31} \mathrm{~A}$ case series published in 2007 of 43 patients treated with RSA with mean follow up of 22 months demonstrated satisfactory shoulder mobility and mean Constant score of $66 \%{ }^{33}$ Subsequently, more case series are continuing to be published regularly in the literature showing promising results with good functional outcomes when RSA is used. ${ }^{34-37}$

In comparison to HA, RSA has generally better functional outcomes and patient satisfaction with many published articles supporting its use, especially in those over the age of 65 . Since 2013 , RSA has replaced HA as the most commonly implanted prosthesis in type 3-4 proximal humeral fractures in patients over 65 years of age. $^{30}$
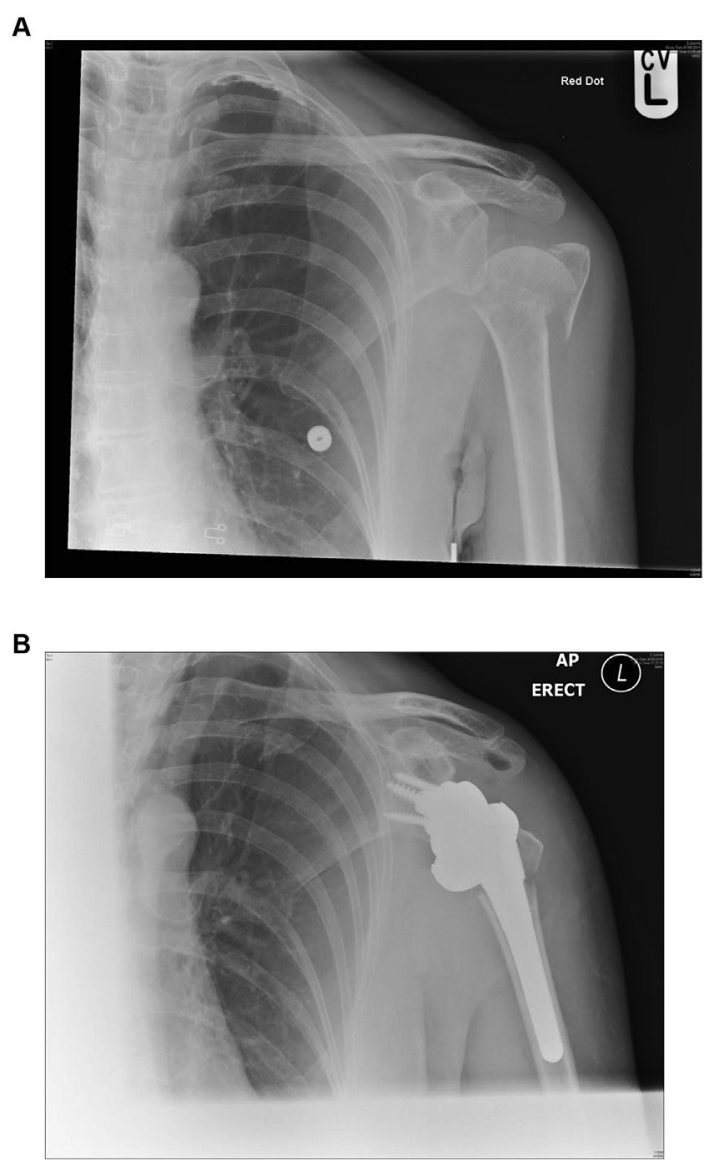

Fig. 2. a \& b: Pre and post-operative radiographs of implantation of RSA for a proximal humeral fracture. 
A systematic review published in 2013 reported that RSA has improved forward flexion. It also reported better functional outcome scores and no difference in complication rates when compared to HA. ${ }^{38}$ The review included 15 studies of whom 9 were case series. However, another systematic review of mainly case series of similar demographics reported findings of improvement in function, pain control and range of movement in both the RSA and the HA groups with slightly higher complication rates in the RSA group. ${ }^{23}$ The authors concluded that patients and surgeons should consider the benefit of surgery before choosing the correct implant.

In 2014 a therapeutic prospective non-randomised trial compared the functional outcomes between 12 and 20 patients treated with HA and RSA, respectively. ${ }^{39}$ The mean Constant score was significantly better in both groups compared to non-operative management. The RSA group showed a higher improvement of Constant score with less reported complications. However, the improvement in Constant score failed to reach statistical significance $(\mathrm{p}=0.06)$. Another more recent blinded RCT from Spain compared the functional outcomes of 62 patients over the age of 70 equally divided between HA and RSA with a mean follow-up of 28.5 months. ${ }^{40}$ The study showed that the reverse shoulder group had better function, pain control and reduced revision rates $(\mathrm{p}<0.001)$.

A number of complications have been reported in the literature. Scapular notching remains the most frequent complication associated with RSA leading to polyethelene wear, synovitis, and glenoid component loosening due to bone loss. ${ }^{33}$ A survey of 77 patients concluded a $44 \%$ prevalence of scapular notching in patients treated for RSA. ${ }^{41}$ Other acute complications include neurovascular injury (11.6\%), iatrogenic fractures (2.3\%), acromial spine fractures (2.3\%), dislocation (2.3\%) and complex regional pain syndrome (7\%). ${ }^{33}$ Acromial insufficieny fractures following RSA resulted in inferior outcomes. ${ }^{42}$ Avoidance of arm lengthening plays a part in reducing brachial plexus strain and transient neurologic deficit, which has been reported to affect up to $22 \%$ of patients. $^{43}$

Boileau et al. introduced a radiographic classification that predict prognosis following prosthetic implantation based on fracture sequalae of multi-fragmented proximal humeral fractures. ${ }^{44}$ This classification specifically looks at whether tuberosities mobilisation is necessary when prosthesis is used (Fig. 3). The authors recommended unconstrained implant (HA) for type 1 and 2 fractures as mobilisation of the tuberosities is not needed provided that the cuff is not injured. However, type 3 and 4 fractures would need mobilisation of tuberosities and hence, RSA is recommended. ${ }^{45}$ Tuberosity osteotomy and mobilisation has a high risk of osteonecrosis leading to high rate of rotator cuff failure and dysfunction. ${ }^{45}$

\section{Discussion}

Over the past 70 years, proximal humeral fracture prevalence has increased due to an ageing population. The increased demands on healthcare and the resultant socioeconomical burden as well as advances in surgery continue to drive change in how we manage proximal humerual fractures. The vast majority of them are minimally displaced fractures and successfully treated non-operatively.

However, surgical management remains controversial in comminuted 3-4 part fractures in particular in the subset of patients with osteoporotic bone in the patients over the age of 65 years old. Despite advances in open reduction and fracture fixation, patients' functional outcomes and satisfaction remains stagnated. In 2015, the United Kingdom Proximal Fracture of the Humerus Evaluation by Randomisation (PROFHER) multicentre RCT of 231 patients reported no difference in patient functional outcomes and quality of life whether treated surgically (fixation or HA replacement) or not. ${ }^{4}$ The finding of this trial sent shockwaves in the Trauma and Orthopaedic community and questioned the current approach to proximal humeral fracture management.

However, despite fulfilling the inclusion criteria, 100 patients were excluded due to associated dislocation and further 87 patients were excluded by the participating 66 surgeons who felt the patient would do better with surgery. Only $4.4 \%$ of the included patients

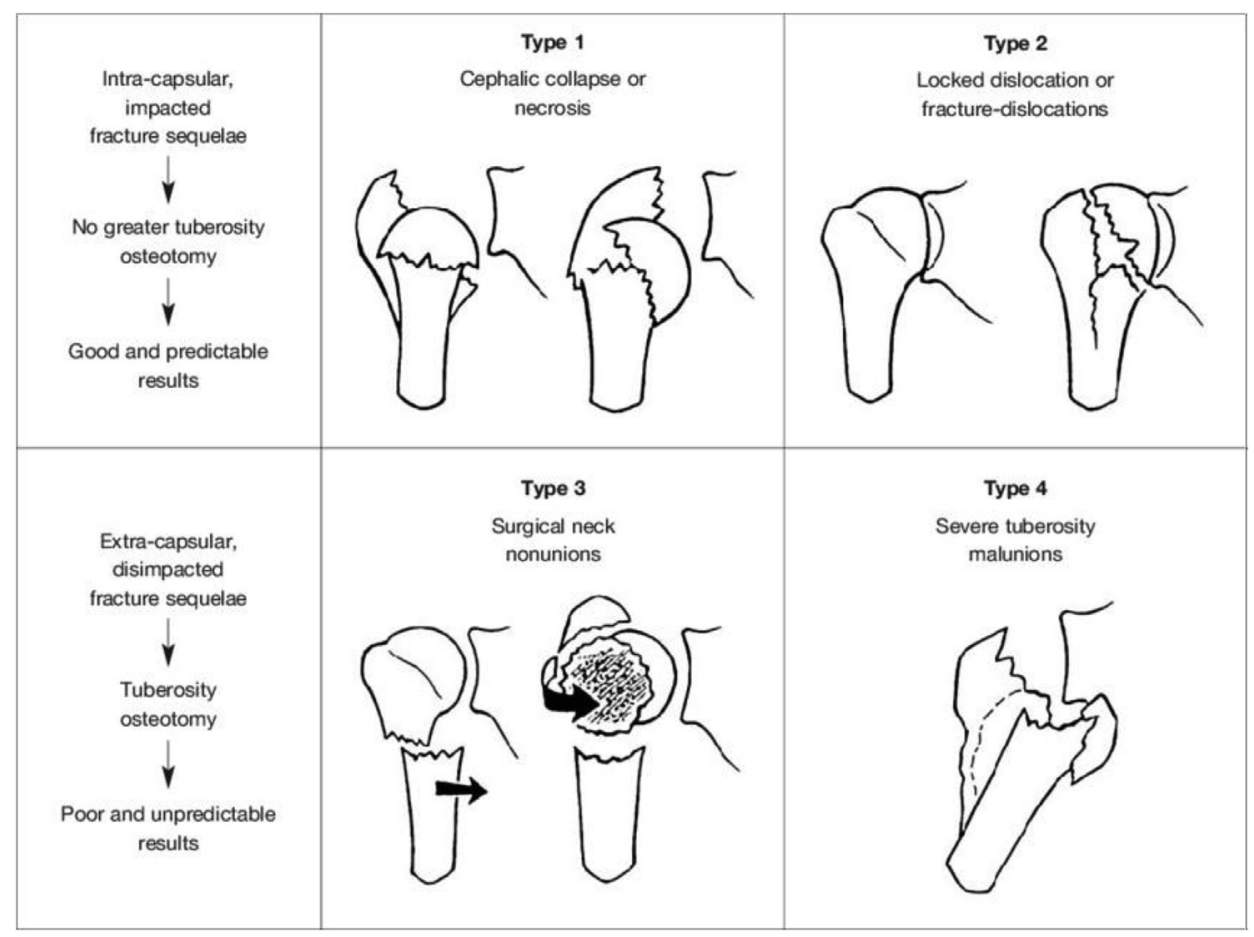

Fig. 3. Radiographic classification to predict need for mobilisation of tuberosities in arthroplasty. 
had part-4 type fractures which is much lower than what is observed in the population (20-30\%). ${ }^{46}$ The excluded patients fundamentally are those recommended for fixation or replacement.

A recent meta-analysis of seven RCTs ( 3 sling vs ORIF, 3 sling vs HA and one HA vs RSA) published in 2017 specifically looking at the management of 3-4 part proximal humeral fractures concluded that RSA results in a improved clinical outcomes and reduced complication rates, with ORIF performing the worst. ${ }^{47}$ This again swings the consensus toward intervention, in particular, RSA.

Currently, there are three ongoing multicentre RCTs looking into the management of proximal humeral fractures. The Norway-based multicentre RCT looking at Displaced Proximal Humeral Fractures treatment with Delta RSA Prosthesis versus Philos plate ORIF in the elderly (DELPHI-trial) is due to report in $2019 .^{48}$ Another ongoing RCT from Australia currently investigating Reverse Shoulder Arthroplasty for the Treatment of Proximal Humeral Fractures in the Elderly versus non-operative treatment (ReShAPE-trial) is due to report in the coming two years. ${ }^{49}$ Finally, the PROFHER-2 trial is in the recruiting phase with authors specifically aiming to address the shortfalls of the first trial and expected to report in $2024 .^{50}$ PROFHER-2 is specifically looking at the management of the 3-4 part comminuted fractures in the over the 65-year olds with 3 arms in the study: conservative management, HA or RSA.

\section{Conclusion}

Management of proximal humeral fractures continues to be a challenging task. There is a lack of consensus on the surgical management of complex or comminuted fractures especially in the elderly. There is good evidence to restrict the use of HA to nonreconstructable comminuted fractures in young patients with good rotator cuff function, and in older patients that are not suitable for conservative management but could not tolerate more complex operations. RSA has shown promising results in the elderly, but there is no long-term functional outcome data to support its use in the wider public. Recent doubts have been cast on the surgical management in general, though more robust level I evidence studies are due to report in the coming few years.

\section{Conflict of interest}

None.

\section{References}

1. Lanting B, MacDermid J, Drosdowech D, Faber KJ. Proximal humeral fractures: a systematic review of treatment modalities. J Shoulder Elb Surg. 2008;17(1): $42-54$.

2. Kannus P, Palvanen M, Niemi S, Parkkari J, Jarvinen M, Vuori I. Increasing number and incidence of osteoporotic fractures of the proximal humerus in elderly people. BMJ. 1996:313(7064):1051-1052.

3. Maravic M, Briot K, Roux C, College Francais des Medecins R. Burden of proximal humerus fractures in the French national hospital database. Orthop Traumatol Surg Res. 2014;100(8):931-934.

4. Rangan A, Handoll H, Brealey S, et al. Surgical vs nonsurgical treatment of adults with displaced fractures of the proximal humerus: the PROFHER randomized clinical trial. JAMA. 2015;313(10):1037-1047.

5. Acevedo DC, Vanbeek C, Lazarus MD, Williams GR, Abboud JA. Reverse shoulder arthroplasty for proximal humeral fractures: update on indications, technique, and results. J Shoulder Elb Surg. 2014;23(2):279-289.

6. Sproul RC, Iyengar JJ, Devcic Z, Feeley BT. A systematic review of locking plate fixation of proximal humerus fractures. Injury. 2011;42(4):408-413.

7. Maier D, Jaeger M, Izadpanah K, Strohm PC, Suedkamp NP. Proximal humeral fracture treatment in adults. I Bone Joint Surg Am. 2014:96(3):251-261.

8. Neer 2 nd CS. Articular replacement for the humeral head. J Bone Joint Surg Am. $1955 ; 37-A(2): 215-228$.

9. Neer 2nd CS. Displaced proximal humeral fractures. II. Treatment of three-part and four-part displacement. J Bone Joint Surg Am. 1970;52(6):1090-1103.

10. Bastian JD, Hertel R. Initial post-fracture humeral head ischemia does not predict development of necrosis. J Shoulder Elb Surg. 2008;17(1):2-8.

11. Kralinger $F$, Schwaiger $R$, Wambacher $M$, et al. Outcome after primary hemiarthroplasty for fracture of the head of the humerus. A retrospective multicentre study of 167 patients. J Bone Joint Surg Br. 2004;86(2):217-219.

12. Robinson CM, Page RS, Hill RM, Sanders DL, Court-Brown CM, Wakefield AE. Primary hemiarthroplasty for treatment of proximal humeral fractures. J Bone Joint Surg Am. 2003;85-A(7):1215-1223.

13. Boileau P, Krishnan SG, Tinsi L, Walch G, Coste JS, Mole D. Tuberosity malposition and migration: reasons for poor outcomes after hemiarthroplasty for displaced fractures of the proximal humerus. J Shoulder Elb Surg. 2002;11(5): 401-412.

14. Boileau P, Gonzalez JF, Chuinard C, Bicknell R, Walch G. Reverse total shoulder arthroplasty after failed rotator cuff surgery. J Shoulder Elb Surg. 2009;18(4): 600-606.

15. Gerber C, Pennington SD, Nyffeler RW. Reverse total shoulder arthroplasty. J Am Acad Orthop Surg. 2009;17(5):284-295.

16. Wall B, Nove-Josserand L, O'Connor DP, Edwards TB, Walch G. Reverse total shoulder arthroplasty: a review of results according to etiology. J Bone Joint Surg Am. 2007;89(7):1476-1485.

17. Browner BD, Jupiter JB, Krettek C, Anderson P. Skeletal Trauma : Basic Science, Management, and Reconstruction. fifth ed. ed. Elsevier/Saunders; 2015.

18. Walch G, Boileau P, Noel E. Shoulder arthroplasty: evolving techniques and indications. Jt Bone Spine. 2010;77(6):501-505.

19. Neer 2nd CS, Watson KC, Stanton FJ. Recent experience in total shoulder replacement. J Bone Joint Surg Am. 1982;64(3):319-337.

20. Boileau P, Walch G. The three-dimensional geometry of the proximal humerus. Implications for surgical technique and prosthetic design. J Bone Joint Surg Br. 1997;79(5):857-865.

21. Grammont PM, Baulot E. Delta shoulder prosthesis for rotator cuff rupture. Orthopedics. 1993;16(1):65-68.

22. Sirveaux F, Favard L, Oudet D, Huquet D, Walch G, Mole D. Grammont inverted total shoulder arthroplasty in the treatment of glenohumeral osteoarthritis with massive rupture of the cuff. Results of a multicentre study of 80 shoulders. J Bone Joint Surg Br. 2004;86(3):388-395.

23. Namdari S, Horneff JG, Baldwin K. Comparison of hemiarthroplasty and reverse arthroplasty for treatment of proximal humeral fractures: a systematic review. J Bone Joint Surg Am. 2013;95(18):1701-1708.

24. Kontakis G, Koutras C, Tosounidis T, Giannoudis P. Early management of proximal humeral fractures with hemiarthroplasty: a systematic review. J Bone Joint Surg Br. 2008;90(11):1407-1413.

25. Stableforth PG. Four-part fractures of the neck of the humerus. J Bone Joint Surg Br. 1984;66(1):104-108.

26. Cai M, Tao K, Yang C, Li S. Internal fixation versus shoulder hemiarthroplasty for displaced 4-part proximal humeral fractures in elderly patients. Orthopedics. 2012;35(9):e1340-e1346.

27. Olerud P, Ahrengart L, Ponzer S, Saving J, Tidermark J. Hemiarthroplasty versus nonoperative treatment of displaced 4-part proximal humeral fractures in elderly patients: a randomized controlled trial. J Shoulder Elb Surg. 2011;20(7): 1025-1033.

28. Boons HW, Goosen JH, van Grinsven S, van Susante JL, van Loon CJ. Hemiarthroplasty for humeral four-part fractures for patients 65 years and older: a randomized controlled trial. Clin Orthop Relat Res. 2012;470(12):3483-3491.

29. Levy J, Frankle M, Mighell M, Pupello D. The use of the reverse shoulder prosthesis for the treatment of failed hemiarthroplasty for proximal humeral fracture. J Bone Joint Surg Am. 2007;89(2):292-300.

30. Rajaee SS, Yalamanchili D, Noori N, et al. Increasing use of reverse total shoulder arthroplasty for proximal humerus fractures in elderly patients. Orthopedics. 2017;40(6):e982-e989.

31. Schairer WW, Nwachukwu BU, Lyman S, Craig EV, Gulotta LV. Reverse shoulder arthroplasty versus hemiarthroplasty for treatment of proximal humerus fractures. J Shoulder Elb Surg. 2015;24(10):1560-1566.

32. Boyle MJ, Youn SM, Frampton CM, Ball CM. Functional outcomes of reverse shoulder arthroplasty compared with hemiarthroplasty for acute proximal humeral fractures. I Shoulder Elb Surg. 2013;22(1):32-37.

33. Bufquin T, Hersan A, Hubert L, Massin P. Reverse shoulder arthroplasty for the treatment of three- and four-part fractures of the proximal humerus in the elderly: a prospective review of 43 cases with a short-term follow-up. J Bone Joint Surg Br. 2007;89(4):516-520.

34. Ross M, Hope B, Stokes A, Peters SE, Mcleod I, Duke PF. Reverse shoulder arthroplasty for the treatment of three-part and four-part proximal humeral fractures in the elderly. I Shoulder Elb Surg. 2015;24(2):215-222.

35. Raiss P, Alami G, Bruckner T, et al. Reverse shoulder arthroplasty for type 1 sequelae of a fracture of the proximal humerus. Bone Joint J. 2018;100-B(3): 318-323.

36. Russo R, Della Rotonda G, Cautiero F, Ciccarelli M. Reverse shoulder prosthesis to treat complex proximal humeral fractures in the elderly patients: results after 10-year experience. Musculoskelet Surg. 2015;99(Suppl 1):S17-S23.

37. Grubhofer F, Wieser K, Meyer DC, et al. Reverse total shoulder arthroplasty for acute head-splitting, 3- and 4-part fractures of the proximal humerus in the elderly. J Shoulder Elb Surg. 2016;25(10):1690-1698.

38. Mata-Fink A, Meinke M, Jones C, Kim B, Bell JE. Reverse shoulder arthroplasty for treatment of proximal humeral fractures in older adults: a systematic review. J Shoulder Elb Surg. 2013;22(12):1737-1748.

39. Alentorn-Geli E, Guirro P, Santana F, Torrens C. Treatment of fracture sequelae of the proximal humerus: comparison of hemiarthroplasty and reverse total shoulder arthroplasty. Arch Orthop Trauma Surg. 2014;134(11):1545-1550.

40. Sebastia-Forcada E, Cebrian-Gomez R, Lizaur-Utrilla A, Gil-Guillen V. Reverse 
shoulder arthroplasty versus hemiarthroplasty for acute proximal humeral fractures. A blinded, randomized, controlled, prospective study. J Shoulder Elb Surg. 2014;23(10):1419-1426.

41. Simovitch RW, Zumstein MA, Lohri E, Helmy N, Gerber C. Predictors of scapular notching in patients managed with the Delta III reverse total shoulder replacement. J Bone Joint Surg Am. 2007;89(3):588-600.

42. Walch G, Mottier F, Wall B, Boileau P, Mole D, Favard L. Acromial insufficiency in reverse shoulder arthroplasties. J Shoulder Elb Surg. 2009;18(3):495-502.

43. Ladermann A, Lubbeke A, Melis B, et al. Prevalence of neurologic lesions after total shoulder arthroplasty. J Bone Joint Surg Am. 2011;93(14):1288-1293.

44. Boileau P, Chuinard C, Le Huec JC, Walch G, Trojani C. Proximal humerus fracture sequelae: impact of a new radiographic classification on arthroplasty. Clin Orthop Relat Res. 2006;442:121-130.

45. Kilic M, Berth A, Blatter G, et al. Anatomic and reverse shoulder prostheses in fracture sequelae of the humeral head. Acta Orthop Traumatol Turcica. 2010;44(6):417-425.

46. Dean BJ, Jones LD, Palmer AJ, et al. A review of current surgical practice in the operative treatment of proximal humeral fractures: does the PROFHER trial demonstrate a need for change? Bone Joint Res. 2016;5(5):178-184.

47. Du S, Ye J, Chen H, Li X, Lin O. Interventions for Treating 3- or 4-part proxima humeral fractures in elderly patient: a network meta-analysis of randomized controlled trials. Int J Surg. 2017;48:240-246.

48. Fjalestad T, Iversen P, Hole MO, Smedsrud M, Madsen JE. Clinical investigation for displaced proximal humeral fractures in the elderly: a randomized study of two surgical treatments: reverse total prosthetic replacement versus angular stable plate Philos (The DELPHI-trial). BMC Musculoskelet Disord. 2014;15:323.

49. Smith GC, Bateman E Cass B, et al, Reverse Shoulder Arthroplasty for the treatment of Proximal humeral fractures in the Elderly (ReShAPE trial) : study protocol for a multicentre combined randomised controlled and observationa trial. Trials. 2017;18(1):91.

50. Tharmanathan P. Effectiveness and cost-effectiveness of reverse shoulde arthroplasty versus hemiarthroplasty versus non-surgical care for acute 3 and 4 part fractures of the proximal humerus in patients aged over 65 years - the PROFHER-2 randomised trial 2017 [cited 2017. Available from: http://www. isrctn.com/ISRCTN76296703. 